\title{
Importance of mental performance in parental choice of food for children aged 4-10 years: a study in four European countries
}

\author{
Heather Gage ${ }^{1, *}$, Bernadette Egan ${ }^{1}$, Peter Williams², Brigitte Brands ${ }^{3}$, Eszter Györei ${ }^{4}$, \\ Juan-Carlos López-Robles ${ }^{5}$, Cristina Campoy ${ }^{5}$, Tamas Decsi ${ }^{4}$, Berthold Koletzko ${ }^{3}$ and \\ Monique Raats ${ }^{1}$ \\ ${ }^{1}$ Food, Consumer Behaviour and Health Research Centre, University of Surrey, Guildford, Surrey, GU2 7XH, UK: \\ ${ }^{2}$ Department of Mathematics, University of Surrey, Guildford, Surrey, UK: ${ }^{3}$ Dr. von Hauner Children's Hospital, \\ Ludwig-Maximilians University, Munich, Germany: ${ }^{4}$ Department of Paediatrics, University of Pécs, Pecs, Hungary: \\ ${ }^{5}$ Department of Paediatrics, University of Granada, Granada, Spain
}

Submitted 9 May 2016: Final revision received 3 September 2016: Accepted 11 0ctober 2016: First published online 20 December 2016

\begin{abstract}
Objective: Typically, attention focuses on how nutrition affects physical health. The present study investigated the importance that parents attach to the impact of diet on mental performance when choosing food for their child.

Design: Questionnaire.

Setting: Four European countries.

Subjects: Parents of children aged 4-10 years ( $n$ 1574): England ( $n$ 397), Germany ( $n$ 389), Hungary ( $n$ 398) and Spain ( $n$ 390).

Results: Most parents (80-85\%) considered the effect of food on four elements of mental performance (child's ability to learn, attention, behaviour, mood) to be moderately, very, extremely ( $v$. slightly, not at all) important in food choices; over $90 \%$ considered healthiness of food and making food appealing to their child important; $79.8 \%$ cost; $76.8 \%$ convenience. Belief that food affects mental performance was $57.4 \%$ (ability to learn), 60.5\% (attention); less than $40 \%$ of parents agreed they were aware which foods had an effect. Parents with lower general interest in healthy eating were less likely to consider the effect of food on mental performance elements as important. Respondents from Germany were more likely to rate mental performance as important (except behaviour); those in Hungary less likely. The most important influence on parents' decisions about feeding their child was their own experience, except Spain, where family/friends/ health professionals were more important.

Conclusions: Nutrition affects brain development and cognitive functioning. Low prioritisation of the effect of food on mental performance indicates potential for educating parents.
\end{abstract}

Parents are the main gatekeepers of the diet of children under the age of 10 years, exerting significant control over what they eat through selection of the range of foods that are offered ${ }^{(1)}$ and methods such as restriction and rewards ${ }^{(2)}$. In making food choices for their children, research has shown that parents are aware of the importance of developing good eating habits for long-term health and are concerned with balancing a healthy diet with their child's food preferences ${ }^{(3)}$. Even though parents associate some foods (such as sugary drinks) with effects on mood and behaviour ${ }^{(4)}$, most perceive that diet has a stronger impact on the physical development of their child than on his/her mental performance ${ }^{(5)}$. Food and nutrition, however, have important and pervasive impacts on brain development and cognitive functioning through effects on cell structure, neurotransmission, energy supply to the brain and metabolism ${ }^{(6,7)}$. Beyond the role of specific nutrients, eating patterns such as skipping breakfast are considered to contribute to poor mental performance ${ }^{(8)}$ and consumption of foods containing certain additives to result in behaviour changes ${ }^{(9)}$. Hence a balanced diet is important for mental as well as physical development with implications for school performance, attainment and well-being in adulthood ${ }^{(10,11)}$.

The present paper reports the findings from a questionnaire study involving the parents of children aged 4-10 years in a convenience sample of four European countries (England, Germany, Hungary and Spain). 
The countries included were those participating in a larger European programme of work on the role that diet plays in the mental performance of children (NUTRIMENTHE project). Since traditionally most attention has been paid to how nutrition affects physical health, the questionnaire particularly probed the extent to which parents took account of the impact of their food choices on the mental performance of their children. The findings reported herein relate to: (i) the relative importance of perceived healthiness, impact on elements of mental performance, attributes of food such as taste, and cost and convenience of preparation in parental food choices; (ii) the awareness and beliefs of parents about the effect of food on their child's ability to learn and attention; (iii) the characteristics of parents associated with the prioritisation of mental performance when choosing food for their children; and (iv) the main influences on parental decision making, including roles of family, friends, health professionals and the media. The inclusion of four different countries enables cultural differences to be explored.

\section{Methods}

\section{Questionnaire development}

The questionnaire was developed by members of the international research teams through several face-to-face meetings and intervening email exchanges. A preliminary questionnaire was developed in English and translated into local languages. It was piloted in all four countries with a small number of local volunteer parents to ensure that the type, flow and number of questions were appropriate to the aims of the study and to pre-test for clarity and comprehension. Results from the pilots were evaluated and compared and the content of the final questionnaire (comprising twenty-five items) agreed. Changes following the pilot involved refinement of the wording to ensure consistency in meaning across the four countries.

The first of three items on food choice asked parents to what extent (not at all/slightly/moderately/very much/ extremely/don't know) they took account of eleven different factors when preparing food for their child. They were also asked to rank their top three factors. The order in which the factors were presented to respondents was rotated. The factors were selected with reference to the relevant theoretical and empirical literature and in discussion with four nutrition and psychology experts. They were divided into four groups: (i) the effect of food on physical functioning (healthiness of food, child's energy levels); (ii) the effect of food on four elements of their child's mental performance (ability to learn, attention, mood, behaviour); (iii) food-related factors (flavour, providing variety, child's food preferences); and (iv) pragmatic factors (cost, ease of preparation).

The findings from qualitative interviews with parents in each country were consulted to guide the selection of elements of mental performance ${ }^{(3)}$. Parents encountered problems with articulating what the concept of 'mental performance' meant to them. Cognitive processes encompass a range of complex functions (perception, psychomotor, attention, memory, language, executive functions) ${ }^{(6)}$, the details of which may be hard for lay people to comprehend. Parents tended to relate most to 'attention' and 'concentration', and many expressed the view that food affected these dimensions indirectly through its impact on mood and behaviour. Consistent with findings from other research $^{(12,13)}$, parents also related to 'learning' as an element of mental performance ${ }^{(6)}$. The selection of indicators of mental performance for the questionnaire in the present study reflected these considerations and the need to ensure that the terminology used was meaningful to parents.

Second, to gain more understanding of the importance parents attribute to the effect of food on mental performance, respondents were asked the extent to which they agreed or disagreed (5-point Likert scale) with two statements: one relating to their awareness of foods that improve their child's attention and ability to learn; the other to their belief that food improves their child's attention and ability to learn. The final item related to the extent (not at all/slightly/ moderately/very much/extremely/don't know) to which parents' decisions about how to feed their child were influenced by eleven different sources (including self, partner, other family, friends, health professionals and various media sources).

In addition, information was collected on the sociodemographic characteristics of respondents that might influence their views and behaviours: age, sex, ethnicity, whether born in the country, highest level of education attained, occupation of main earner, number of children living at home, if respondent had ever gained a qualification relating to health or nutrition, and smoking status. Respondents also completed the General Health Interest (GHI) scale, an eight-item instrument that measures health-related food attitudes, each scored on a 7-point scale from which an average is calculated, range 1 (least interested in healthy eating) to 7 (most interested) ${ }^{(14)}$.

\section{Recruitment of participants}

In order to access national samples, data collection was managed by a market research agency in England that had links with partner organisations in the other three countries. Parents were recruited from established panels in each country. Panel members are selected according to the inclusion criteria for individual studies, which, in the present study, were that parents had a child aged 4-10 years old, in mainstream (not private or special) education. The focus on 4-10-year-old children was because, at that age, parents are still likely to be having a significant influence over their diet and nutrition. Parents of children with diagnosed pathologies, such as attention-deficit hyperactivity disorder, were excluded because it was reasoned that they may have researched dietary influences on development more 
thoroughly than the general population. The questionnaire was distributed and completed online in the spring of 2011. Controls in the questionnaire prevented non-response to any item so all returns were complete. Ethical approval was gained from the University of Surrey research ethics committee.

\section{Sample size}

The target was to recruit 400 parents in each country, enabling the detection, using a two-sided test, with size of $5 \%$ and power of $80 \%$, of an underlying difference in prevalence of $10 \%$ with regard to any dichotomous outcome.

\section{Analysis}

Data were transferred to the statistical software package SPSS version 16 for analysis. Summary statistics (numbers, percentages, means, standard deviations, medians, ranges) were calculated for all background variables and broken down by country. Comparisons between countries were performed using the appropriate statistical tests.

Factors in food choice were ranked according to the proportions of parents responding that they took account of the factor extremely, very much or moderately ( $v$. slightly or not at all). Factors were also ranked for the proportion of respondents placing the factor among one of the top three. Rankings were compared between countries, and between parents with different sex mixes of children, because boys are generally regarded as needing more energy (at a given age) than girls ${ }^{(15)}$.

The proportions of parents agreeing or strongly agreeing that they were not aware of which foods contribute to attention and ability to learn, and did not believe foods impact on attention and ability to learn, were analysed descriptively and compared between countries.

Backwards stepwise logistic regression modelling was undertaken to explore associations between parents' background characteristics and stating that they take account of each of the four mental performance factors slightly or not at all ( $v$. moderately, very much or extremely) in making food choices for their child.

The importance of different sources of information used by parents in food choice decisions was re-coded on a 5-point scale $(1=$ not at all to $5=$ extremely; don't know treated as missing). The eleven sources were combined into four groups for analysis: self (i.e. own common sense), family and friends, doctor and health professionals, and media (comprising seven items: radio, television, websites, social networks, advertisements, books, magazines). A mean score was calculated for each parent for each group. Country-level means were then compared.

\section{Results}

\section{Sample characteristics}

Questionnaires were returned by 1606 parents with children aged between 4 and 10 years ( $n 401$ in England,
Germany, Hungary; $n 403$ in Spain), but the children were not co-resident with some of the respondents. Since the questions specifically referred to food choice for 'their child', those parents with no children living with them were excluded from the analysis. This left a total sample of 1574 respondents. Respondents were predominantly of white ethnicity. Parent responders differed significantly across countries in all characteristics except for smoking rates (overall, 25.9\% were current smokers) and having a qualification in health and nutrition (11.8\%; Table 1).

\section{Factors affecting food choices}

Across all countries, the proportions of parents stating they took account of a factor extremely, very much or moderately ( $v$. slightly or not at all) when making food choices for their child were lowest for the pragmatic factors of cost $(79.8 \%)$ and convenience $(76.8 \%)$ and highest for healthiness of food, making food appealing to their child and the perceived effect of food on energy levels (over $90 \%$ ). Between 80 and $85 \%$ of parents considered the impact of food on the four elements of mental performance to be moderately, very much or extremely important. Differences existed between countries in the importance that parents said they attached to cost, flavour of food, child's preferences, providing variety and the effect of food on child's mood and attention (but not with respect to the effect of food on the child's energy levels, ability to learn, behaviour, ease of preparation or the healthiness of food; Table 2).

These rankings altered somewhat when the proportions of parents listing a factor in the top three most important were examined. Healthiness (80.3\%), offering variety $(57 \cdot 1 \%)$ and the child's food preferences (41.9\%) were the most important to parents. A middle group of factors comprised the effect of food on the child's energy $(28.0 \%)$, flavour of food $(27.3 \%)$ and cost $(20 \cdot 8 \%)$. Ease of preparation and the four factors relating to the child's mental performance were all ranked in the top three factors by less than $10 \%$ of respondents (Table 2).

Differences existed between countries in the proportions ranking factors in the top three for all factors except healthiness, where there was close agreement. Compared with the other countries, respondents in Hungary were less likely to rate the four elements of mental performance among the top three factors influencing their food choices, while those in Germany were more likely to do so (other than behaviour). The child's food preferences were important in Hungary, and less so in Spain, where variety and providing energy were relatively important considerations (Table 2). In Germany, low proportions of parents considered variety of food as important. Cost was relatively unimportant in both Germany and Spain. Ease of 
Table 1 Characteristics of respondents and comparison across countries: convenience sample of parents of children aged 4-10 years from four European countries, 2011

\begin{tabular}{|c|c|c|c|c|c|c|c|c|c|c|c|}
\hline \multirow[b]{2}{*}{ Characteristic } & \multicolumn{2}{|c|}{$\begin{array}{l}\text { All countries } \\
(n \text { 1574) }\end{array}$} & \multicolumn{2}{|c|}{$\begin{array}{l}\text { England } \\
(n \text { 397) }\end{array}$} & \multicolumn{2}{|c|}{$\begin{array}{l}\text { Germany } \\
(n \text { 389) }\end{array}$} & \multicolumn{2}{|c|}{$\begin{array}{l}\text { Hungary } \\
(n \text { 398) }\end{array}$} & \multicolumn{2}{|c|}{$\begin{array}{l}\text { Spain } \\
(n 390)\end{array}$} & \multirow{2}{*}{$\begin{array}{l}\text { Difference betweer } \\
\text { countries, } P\end{array}$} \\
\hline & $n$ & $\%$ & $n$ & $\%$ & $n$ & $\%$ & $n$ & $\%$ & $n$ & $\%$ & \\
\hline \multicolumn{12}{|l|}{ Age (years) } \\
\hline $18-24$ & 96 & $6 \cdot 1$ & 20 & $5 \cdot 0$ & 48 & $12 \cdot 3$ & 4 & 1.0 & 24 & $6 \cdot 2$ & $0.031 \ddagger$ \\
\hline $25-34$ & 514 & 32.7 & 141 & 35.5 & 127 & $32 \cdot 6$ & 137 & 34.4 & 109 & 27.9 & \\
\hline $35-44$ & 678 & $43 \cdot 1$ & 144 & $36 \cdot 3$ & 141 & $36 \cdot 2$ & 210 & $52 \cdot 8$ & 183 & 46.9 & \\
\hline$\geq 45$ & 286 & $18 \cdot 2$ & 92 & $23 \cdot 2$ & 73 & $18 \cdot 8$ & 47 & $11 \cdot 8$ & 74 & $19 \cdot 0$ & \\
\hline \multicolumn{12}{|l|}{ Sex } \\
\hline Male & 598 & 38.0 & 127 & $32 \cdot 0$ & 166 & $42 \cdot 7$ & 128 & $32 \cdot 2$ & 177 & $45 \cdot 4$ & $<0.001 \S$ \\
\hline Born in home country & & & & & & & & & & & \\
\hline Yes & 1475 & 93.7 & 354 & $89 \cdot 2$ & 366 & $94 \cdot 1$ & 386 & $97 \cdot 0$ & 369 & $94 \cdot 6$ & $<0.001 \S$ \\
\hline \multicolumn{12}{|l|}{ Qualification health/nutrition } \\
\hline \multicolumn{5}{|l|}{ Ever smoked } & 51 & $13 \cdot 1$ & 57 & $14 \cdot 3$ & 42 & $10 \cdot 8$ & $0.097 \S$ \\
\hline $\begin{array}{l}\text { Yes } \\
\text { Current smoker }\end{array}$ & 870 & $55 \cdot 3$ & 209 & $52 \cdot 6$ & 217 & $55 \cdot 8$ & 219 & $55 \cdot 0$ & 225 & $57 \cdot 7$ & $0.555 \S$ \\
\hline $\begin{array}{l}\text { Yes } \\
\text { Ethnicity }\end{array}$ & 408 & $25 \cdot 9$ & 86 & 21.7 & 111 & $28 \cdot 5$ & 107 & $26 \cdot 9$ & 104 & $26 \cdot 7$ & $0.142 \S$ \\
\hline $\begin{array}{l}\text { White } \\
\text { College/university education }\end{array}$ & 1491 & 94.7 & 356 & $89 \cdot 7$ & 367 & $94 \cdot 3$ & 395 & $99 \cdot 2$ & 373 & $95 \cdot 9$ & $<0.001 \S$ \\
\hline $\begin{array}{l}\text { Yes } \\
\text { Main earner occupation }\end{array}$ & 847 & 53.8 & 263 & $66 \cdot 2$ & 207 & $53 \cdot 2$ & 158 & 39.7 & 219 & $56 \cdot 2$ & $<0.001 \S$ \\
\hline Managerial, professional ${ }^{\star}$ & 545 & $34 \cdot 6$ & 130 & $32 \cdot 7$ & 144 & $37 \cdot 0$ & 120 & $30 \cdot 2$ & 151 & $38 \cdot 7$ & $0.046 \S$ \\
\hline & Mean & SD & Mean & SD & Mean & SD & Mean & SD & Mean & SD & \\
\hline $\begin{array}{l}\text { No. of children }<18 \text { years living with } \\
\text { respondent }\end{array}$ & 1.95 & 0.99 & 1.83 & 0.86 & 1.86 & $1 \cdot 12$ & 1.92 & 0.78 & $2 \cdot 17$ & $1 \cdot 13$ & $<0.001 \|$ \\
\hline $\begin{array}{l}\text { GHI: range } 1-7 \text { (most interested in } \\
\text { healthy eating) } \dagger\end{array}$ & 4.67 & 1.05 & 4.65 & 0.93 & 4.70 & 1.03 & $4 \cdot 37$ & $1 \cdot 15$ & 4.95 & 1.00 & $<0.001 \|$ \\
\hline
\end{tabular}

*Managerial or professional (rather than clerical, administrative, manual, homemaker, retired, student, seeking work).

†General Health Interest scale ${ }^{(14)}$.

fUsing the Kruskal-Wallis test.

§Using the $X^{2}$ test.

\|Using the $t$ test.

preparation was unimportant in all countries but particularly so in Hungary.

\section{Comparing parents with different sex mixes of children}

Of the 1574 parents with children living at home, 536 (34.1\%) had only boys; 385 (24.5\%) had only girls; 653 $(41.5 \%)$ had both boys and girls. Within each country separately, there was no significant difference between parents with only girls, only boys or both in the extent to which parents said they took account of any of the eleven factors or in the proportions that ranked any factor among the top three (data not shown).

Combining all four countries, the sex mix of children had a significant effect on the extent to which parents said they took account of the child's food preferences $(P=0.003)$ and marginally the flavour of food $(P=0 \cdot 077)$. Both these factors were more important to parents who had only girls, than to those who had only boys, or both. There was no significant difference between parents with only girls, only boys or both in the extent to which parents said they took account of any of the other nine factors or in the proportions that ranked any factor in the top three (data not shown).
Awareness and beliefs of parents about the effect of food on their child's ability to learn and attention Across all countries, some $60 \%$ of parents stated that they believed that food affected ability to learn $(57.4 \%)$ or attention (60.5\%). Similar proportions stated they were not aware which foods affected the ability to learn (65.2\%) or attention $(62.2 \%)$ of their child (Table 3$)$. There was a highly statistically significant positive association between stating awareness and belief; for ability to learn, of those aware, $85.9 \%$ also believed; $89.3 \%$ for attention $\left(\chi^{2}\right.$ test, $P<0.0005$ for both). Also, parents stating they were not aware or did not believe were significantly more likely to state they only slightly or not at all ( $v$. moderately, very much or extremely) took account of the effect of foods on their child's ability to learn or attention $\left(\chi^{2}\right.$ test, $P<0.0005$ for each association).

\section{Characteristics of parents prioritising different factors when choosing foods for their children}

Regression modelling identified that parents having a higher GHI mean score were more likely to consider elements of mental performance as being moderately, very or extremely important when making food choices 
Table 2 Factors affecting food provision for children among a convenience sample of parents of children aged 4-10 years from four European countries, 2011

\begin{tabular}{|c|c|c|c|c|c|c|c|c|c|c|c|c|c|c|c|c|c|c|}
\hline \multirow{4}{*}{$\begin{array}{l}\text { Factors influencing food } \\
\text { provision, ranked* }\end{array}$} & \multicolumn{18}{|c|}{ When providing food for your child, to what extent do you take account of the following? } \\
\hline & \multirow{3}{*}{$\begin{array}{l}\text { No. stating } \\
\text { 'don't know' }\end{array}$} & \multicolumn{5}{|c|}{$\begin{array}{c}\text { No. and } \% \text { responding extremely, very } \\
\text { much or moderately ( } v \text {. slightly } \\
\text { or not at all) }\end{array}$} & \multirow{3}{*}{$\begin{array}{l}\text { Factors in top three most important } \\
\text { influences on food provision, ranked }\end{array}$} & \multicolumn{10}{|c|}{ No. and \% ranking factor in top three most important } & \multirow{3}{*}{$\begin{array}{l}\text { Difference } \\
\text { between } \\
\text { countries, } P \S\end{array}$} \\
\hline & & \multicolumn{2}{|c|}{$\begin{array}{l}\text { Overall } \\
\text { ranking }\end{array}$} & \multicolumn{3}{|c|}{ Inter-country differences } & & \multicolumn{2}{|c|}{$\begin{array}{l}\text { All countries } \\
(n \text { 1574) }\end{array}$} & \multicolumn{2}{|c|}{$\begin{array}{l}\text { England } \\
(n \text { 397) }\end{array}$} & \multicolumn{2}{|c|}{$\begin{array}{l}\text { Germany } \\
(n \text { 389) }\end{array}$} & \multicolumn{2}{|c|}{$\begin{array}{l}\text { Hungary } \\
(n \text { 398) }\end{array}$} & \multicolumn{2}{|c|}{$\begin{array}{l}\text { Spain } \\
(n 390)\end{array}$} & \\
\hline & & $n$ & $\%$ & $P+$ & Rank‡ & Sig. diff.ł & & $n$ & $\%$ & $n$ & $\%$ & $n$ & $\%$ & $n$ & $\%$ & $n$ & $\%$ & \\
\hline Healthiness of food & 21 & 1505 & 96.9 & 0.123 & HGES & - & Healthiness of food & 1264 & $80 \cdot 3$ & 321 & $80 \cdot 9$ & 302 & $77 \cdot 6$ & 330 & 82.9 & 331 & 79.7 & 0.305 \\
\hline Offering a variety of food & 24 & 1469 & 94.8 & $<0.001$ & HESG & $\mathrm{HES}>\mathrm{G}$ & Offering a variety of food & 899 & $57 \cdot 1$ & 212 & 53.4 & 162 & 41.6 & 221 & 55.5 & 304 & $77 \cdot 9$ & $<0.001$ \\
\hline Flavour of food & 23 & 1475 & $95 \cdot 1$ & $<0.001$ & HEGS & $H>E G S$ & Child's food preferences & 659 & 41.9 & 138 & $34 \cdot 8$ & 177 & 45.5 & 249 & $62 \cdot 6$ & 95 & 24.1 & $<0.001$ \\
\hline Child's food preferences & 21 & 1474 & 94.9 & $<0.001$ & HGES & $H>E G>S$ & Effect of food on child's energy levels & 440 & 28.0 & 97 & 24.4 & 84 & 21.6 & 90 & $22 \cdot 6$ & 169 & 43.3 & $<0.001$ \\
\hline $\begin{array}{l}\text { Effect of food on child's } \\
\text { energy levels }\end{array}$ & 25 & 1440 & 93.0 & 0.985 & HESG & - & Flavour of food & 429 & $27 \cdot 3$ & 101 & $25 \cdot 4$ & 121 & $31 \cdot 1$ & 114 & 28.6 & 93 & 23.8 & $<0.001$ \\
\hline $\begin{array}{l}\text { Effect of food on child's } \\
\text { behaviour }\end{array}$ & 39 & 1306 & $85 \cdot 1$ & 0.098 & EGSH & - & Cost of foods & 328 & $20 \cdot 8$ & 117 & 29.5 & 58 & 14.9 & 120 & $30 \cdot 2$ & 33 & 8.5 & $<0.001$ \\
\hline $\begin{array}{l}\text { Effect of food on child's } \\
\text { attention }\end{array}$ & 46 & 1291 & 84.5 & 0.013 & GESH & $\mathrm{G}>\mathrm{SH}$ & $\begin{array}{l}\text { Effect of food on child's ability to } \\
\text { learn }\end{array}$ & 152 & 9.7 & 39 & 9.8 & 56 & 14.4 & 15 & 3.8 & 42 & $10 \cdot 8$ & $<0.001$ \\
\hline $\begin{array}{l}\text { Effect of food on child's } \\
\text { mood }\end{array}$ & 48 & 1283 & 84.1 & 0.017 & GEHS & $G>S$ & Effect of food on child's attention & 147 & $9 \cdot 3$ & 32 & 8.1 & 74 & $19 \cdot 0$ & 13 & 3.3 & 28 & $7 \cdot 2$ & $<0.001$ \\
\hline $\begin{array}{l}\text { Effect of food on child's } \\
\text { ability to learn }\end{array}$ & 49 & 1277 & 83.7 & 0.097 & GSHE & - & Ease of preparation & 146 & $9 \cdot 3$ & 46 & $11 \cdot 6$ & 51 & $13 \cdot 1$ & 10 & 2.5 & 39 & $10 \cdot 0$ & $<0.001$ \\
\hline Cost of foods & 23 & 1237 & 79.8 & $<0.001$ & HEGS & $\mathrm{HE}>\mathrm{GS}$ & Effect of food on child's behaviour & 141 & $9 \cdot 0$ & 55 & 13.9 & 31 & 8.0 & 21 & $5 \cdot 3$ & 34 & 8.7 & $<0.001$ \\
\hline Ease of preparation & 24 & 1190 & 76.8 & 0.040 & EGSH & $\mathrm{E}>\mathrm{H}$ & Effect of food on child's mood & 117 & $7 \cdot 4$ & 33 & $8 \cdot 3$ & 51 & $13 \cdot 1$ & 11 & $2 \cdot 8$ & 22 & $5 \cdot 6$ & $<0.001$ \\
\hline
\end{tabular}

${ }^{*}$ Note that order of presentation of factors to respondents was rotated.

HUsing one-way ANOVA based on the 5 -point linear scale $(1=$ not at all to $5=$ extremely).

\#For rank and significant differences (sig. diff.): $\mathrm{E}=$ England, $\mathrm{G}=$ Germany, $\mathrm{H}=$ Hungary and $\mathrm{S}=$ Spain

$\S$ Using the $x^{2}$ test. 


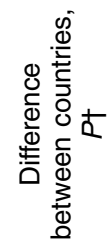

古

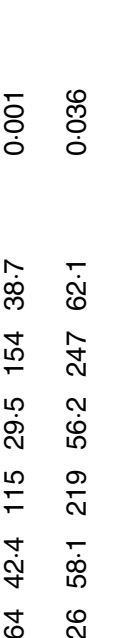

을

๘ $ळ$

एँ $=$

흐융

즘

फ้

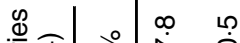

壱志

กิ กิ

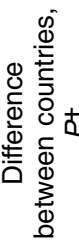

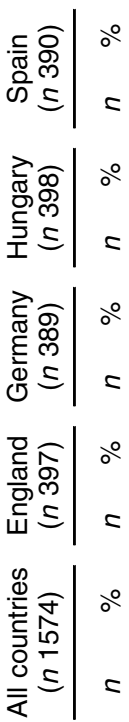

ம்

غं

\&

일

○

iे

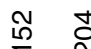

m

से छे

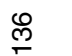

离

$\frac{\sqrt{\frac{\pi}{0}}}{\frac{\pi}{0}}$

然

(1)

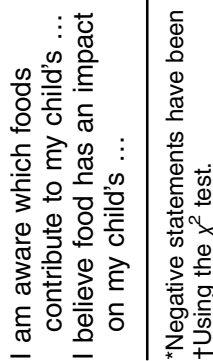

for their child; hence, putting low priority on mental performance factors was associated with less interest in healthy eating. Parents in Germany (compared with those in England) were more likely to consider a child's ability to learn, attention and mood to be moderately, very or extremely important when making food choices for their child. Similarly, parents in Hungary prioritised ability to learn. White ethnicity was associated with increased likelihood of considering a child's behaviour as important in food choices. Having more children in the family made parents less likely to consider the effect of the food on their child's mood to be moderately, very or extremely important in their food choices (Table 4).

\section{Influences on parents' food choice decisions}

Parents reported that their own common sense and experience was the most important influence on decisions about how to feed their child; media sources had little influence in all countries. Differences existed between countries. In contrast to England where parents reported above-average reliance on self and less reliance on family/ friends and health professionals, parents in Spain attributed more importance to family/friends and health professionals and less to their own common sense (Table 5).

\section{Discussion}

Dietary choices are influenced by a complex web of factors, including palatability (taste, smell, texture), nutritional content, calorific value, cost, convenience and the social context ${ }^{(16)}$. Almost all parents in each of the four European countries included in the present study rated healthiness of food to be important when choosing food for their child. Lower proportions (80-85\%) considered the impact of food on their child's attention, ability to learn, mood and behaviour to be important, and even lower proportions (about 60\%) stated they believed that food impacted their child's ability to learn and attention. Cost considerations, food variety, flavour and effect of food on energy levels were all more likely to be rated in the top three factors considered by parents in making food choices than the four elements of mental performance. These findings differ somewhat from those of other European $^{(17)}$ and US ${ }^{(18)}$ food and nutrition surveys which found cost and taste to be more important than healthiness, possibly reflecting a reordering of priorities when selecting foods for children. Neither of these major surveys offered mental performance as factors in food choice, indicating the general focus on food as a determinant of physical rather than cognitive functioning.

Across all countries parents with only girls were more likely to state that their child's food preferences were important in their choice of food for the child than parents who had only boys or a mix of boys and girls. Consistent 
Table 4 Characteristics and country* of parents considering mental performance factor is moderately, very much or extremely ( $v$. not at all or slightly) important when making food choices for their child among a convenience sample of parents of children aged 4-10 years from four European countries, 2011

\begin{tabular}{|c|c|c|c|c|c|c|c|}
\hline \multirow[b]{2}{*}{ Factor in food choice/dependent variable } & \multicolumn{2}{|c|}{ No. stating factor is important } & \multirow[b]{2}{*}{ Significant characteristics } & \multirow[b]{2}{*}{ Exp B十 } & \multirow[b]{2}{*}{$P$} & \multicolumn{2}{|c|}{$95 \% \mathrm{Cl}$} \\
\hline & $\begin{array}{l}\text { Slightly/ } \\
\text { not at all }\end{array}$ & $\begin{array}{l}\text { Moderately/ } \\
\text { very much/ } \\
\text { extremely }\end{array}$ & & & & Lower & Upper \\
\hline \multirow[t]{3}{*}{ Effect of food on child's ability to learn } & 248 & 1277 & GHI mean & 1.638 & $<0.0005$ & 1.451 & 1.925 \\
\hline & & & Germany & 1.477 & 0.033 & 1.033 & $2 \cdot 111$ \\
\hline & & & Hungary & 1.494 & 0.024 & 1.055 & $2 \cdot 116$ \\
\hline \multirow[t]{2}{*}{ Effect of food on child's attention } & 237 & 1291 & GHI mean & $1 \cdot 703$ & $<0.0005$ & $1 \cdot 280$ & 1.959 \\
\hline & & & Germany & 1.510 & 0.025 & 1.054 & $2 \cdot 165$ \\
\hline \multirow[t]{2}{*}{ Effect of food on child's behaviour } & 229 & 1306 & GHI mean & 1.702 & $<0.0005$ & 1.477 & 1.961 \\
\hline & & & White ethnicity & 1.932 & 0.019 & 1.115 & 3.345 \\
\hline \multirow[t]{3}{*}{ Effect of food on child's mood } & 243 & 1283 & Number of children & 0.873 & 0.050 & 0.762 & 1.000 \\
\hline & & & GHI mean & 1.549 & $<0.0005$ & 1.353 & 1.774 \\
\hline & & & Germany & 1.456 & 0.037 & 1.024 & 2.070 \\
\hline
\end{tabular}

*Independent variables/characteristics of parents included in the modelling: total number of children living at home; General Health Interest (GHI) mean score $(1=$ low to $7=$ high interest/healthy eater); ethnicity white (yes $v$. no); age (in six categories); sex; born in country (yes $v$. no); qualification related to health or nutrition (yes $v$. no); university or college education ( $v$. educated to age 18 years at most); country (with England as the reference). Current smoker was omitted due to correlation with GHI: mean (SD) GHI of 1166 non-smokers was $4.73(1.04) v .4 .51(1.08)$ for current smokers $(P<0.0005$, unpaired $t$ test).

†Adjusted odds ratio for considering the effect of food on element of mental performance to be moderately, very or extremely ( $v$. slightly, not at all) important.

with other evidence that shows similarities in parents' feeding styles for boys and girls ${ }^{(19)}$, no other factor in food choice differed according to the sex of the child. It has been shown that parents are likely to modulate their feeding strategies to match each individual child's eating behaviours and that the relationship is complex and interactive $^{(20)}$.

Geographical location can affect access to certain foods, cultural traditions can account for dietary differences, and knowledge and beliefs about the risks and benefits of alternative nutritional decisions influence ability to choose healthy options ${ }^{(21-24)}$. In this regard, differences were found between countries in their rankings of the factors influencing food choices. For example, providing variety was significantly less important to parents in Germany and most important in Spain. Parents in Hungary generally prioritised elements of mental performance less than parents in England; parents in Germany considered them more important (except for the effect of food on behaviour). Cultural differences in attitudes to foods are well recognised $^{(25,26)}$, but accounting for differences between countries in our results is to some extent speculative as this was not explicitly explored by the questionnaire. It may, however, reflect national differences in policies and public health messages ${ }^{(27)}$.

Lower prioritisation of the effect of food on mental performance indicates the potential for educating parents and building public awareness. Recently, public health concerns have focused heavily on childhood obesity ${ }^{(28)}$ and scope exists to redress this imbalance. Uncertainties exist, however, in the scientific evidence about the relationship between dietary intake and mental performance, resulting in a lack of clear messages for consumers ${ }^{(29-32)}$. Poor knowledge and understanding were indicated by parental responses to the survey, with less than $40 \%$ reporting they were aware which foods contributed to ability to learn and attention. Multiple factors affect mental functioning, however, and identifying the independent effect of nutrition, from social, economic, genetic and parenting factors, is challenging ${ }^{(7,29)}$. Further research in this area is required, along with robust dissemination strategies to ensure that key messages about the role of nutrients and eating behaviours, such as skipping breakfast, reach the target audiences ${ }^{(9,33-35)}$. Respondents in each country stated that decisions about food choices for their children were less influenced by media sources than by health professionals, and that they relied on their own experience and common sense the most, so innovative methods of getting messages over may need to be identified. Understanding subgroups of populations is important for effective public policy; for example, parents with lower general interest in healthy eating were less likely to prioritise all mental performance issues, so may warrant special targeting.

Although care was taken in translating and piloting the questionnaire to ensure uniformity between countries, the findings need to be interpreted in the light of a number of limitations. The study was based on a convenience sample of four countries that provided geographical spread across Europe but may not have been socially and politically representative of the whole European population. In order to recruit large national samples, respondents were drawn from market research panels and significant differences existed between countries in some characteristics. Members of panels are volunteers and are typically reimbursed for the time they spend completing online surveys, so the people attracted to this role are self-selected and may not be representative of the general population in each country ${ }^{(36,37)}$. The weakness of such approaches is well documented ${ }^{(38)}$ and further research on the representativeness of online samples has been 
recommended ${ }^{(37)}$. Some $38 \%$ of respondents were men and fathers have been shown to have different attitudes to feeding children to those of mothers ${ }^{(39)}$. At individual and country level, differences were not found between reported awareness and beliefs of men and women about the effect of food. Taking all countries together, however, female respondents were more aware than men of which foods affected their child's attention and ability to learn. Women were also more likely to believe that food affected their child's ability to learn, but there were no differences between men and women in beliefs about the impact of food on their child's attention. The study did not test the nutrition knowledge and understanding of respondents.

Brain development and cognition are important for learning, memory, information processing, reasoning, behaviour and many other functions that affect an individual's life achievements and well-being. Benefit may arise from increasing awareness of the potential role of diet and nutrition in both the brain development and cognitive functioning of children through increasing the quantity and clarity of consumer information ${ }^{(40)}$. Parents in particular are important gatekeepers to a child's diet and central to the environment in which most children's eating habits are developed ${ }^{(41)}$. As such they constitute an important target group for communication on the nutritional properties and health effects of foods. Timely, consistent and evidence-based information, tailored to different groups, and delivered in a variety of formats, is needed to form a basis for rational decision making around food choices ${ }^{(42)}$.

\section{Acknowledgements}

Acknowledgements: The authors are grateful to the parents who participated in the study. Financial support: This work was supported by the European Communities 7 th Framework Programme (NUTRIMENTHE; grant agreement no. 212652). The funder had no role in the design, analysis or writing of this article. Conflict of interest: All the authors declare no conflicts of interest. Authorship: C.C., T.D., B.K., B.E., H.G. and M.R. conceived and designed the study. Data collection and analysis were undertaken by B.B., E.G. and J.-C.L.-R. The statistical analysis was conducted by P.W. The paper was drafted by H.G., B.E. and P.W., and approved by all other authors. Ethics of buman subject participation: Ethical approval was gained from the University of Surrey research ethics committee.

\section{References}

1. Koivisto H (1999) Factors influencing children's food choice. Ann Med 31, Suppl. 1, 26-32.

2. Brown R \& Ogden J (2004) Children's eating attitudes and behaviour: a study of the modelling and control theories of parental influence. Health Educ Res 19, 261-271. 
3. Brands B, Egan B, Györei E et al. (2012) A qualitative interview study on effects of diet on children's mental state and performance. Evaluation of perceptions, attitudes and beliefs of parents in four European countries. Appetite 58, 739-746.

4. Hart K, Herriott A, Bishop J et al. (2003) Promoting healthy diet and exercise patterns amongst primary school children; a qualitative investigation of parents' perspectives. J Hum Nutr Diet 16, 18-96.

5. Egan B, Gage H, Williams P et al. (2016) The effect of diet on the physical and mental development of children: views of parents and teachers in four European countries. $\mathrm{Br} J$ Nutr (Epublication ahead of print version).

6. Schmitt JA, Benton D \& Kallus KW (2005) General methodological considerations for the assessment of nutritional influences on human cognitive functions. Eur J Nutr $\mathbf{4 4}$, 459-464.

7. Isaacs E \& Oates J (2008) Nutrition and cognition: assessing cognitive abilities in children and young people. Eur J Nutr 47, Suppl. 3, 4-24.

8. Bellisle F (2004) Effect of diet on behaviour and cognition in children. Br J Nutr 92, Suppl. 2, S229-S232.

9. Benton D (2008) The influence of children's diet on their cognition and behaviour. Eur J Nutr 47, 25-37.

10. Alderman H, Behrman JR, Lavy V et al. (1997) Child Nutrition, Child Health, and School Enrollment. A Longitudinal Analysis. Policy Research Working Paper. http://elibrary. worldbank.org/doi/abs/10.1596/1813-9450-1700 (accessed December 2016).

11. Associate Parliamentary Food and Health Forum (2008) The links between diet and behaviour. The influence of nutrition on mental health. Report of an inquiry held by the Associate Parliamentary Food \& Health Forum, January 2008. http:// www.fabresearch.org/viewitem.php?id=7302 (accessed May 2015).

12. Russell CG, Flight I, Leppard P et al. (2004) A comparison of paper-and-pencil and computerised method of 'hard' laddering. Food Qual Prefer 15, 279-291.

13. Russell CG, Busson A, Flight I et al. (2004) A comparison of three laddering techniques applied to an example of a complex food choice. Food Qual Prefer 15, 569-583.

14. Roininen K, Lahteenmaki L \& Tuorila H (1999) Quantification of consumer attitudes to health and hedonic characteristics of foods. Appetite 33, 71-88.

15. Zelman K (2002) Estimated calorie requirements. Based on Estimated Energy Requirements (EER) from the Institute of Medicine Dietary Reference Intakes Macronutrients report. http://www.webmd.com/diet/features/estimated-calorierequirement (accessed December 2015).

16. Raats M (2010) The role of consumers. Nestle Nutr Workshop Ser Pediatr Program 66, 161-171.

17. Lappalainen R, Kearney J \& Gibney M (1998) A pan EU survey of consumer attitudes to food, nutrition and health: an overview. Food Qual Prefer 9, 467-478.

18. International Food Information Council Foundation (2011) Food and Health Survey: Consumer Attitudes Toward Food Safety, Nutrition and Health. http://www.foodinsight.org/ Content/3840/2011\%20IFIC\%20FDTN\%20Food\%20and\% 20Health\%20Survey.pdf (accessed May 2015).

19. Webber L, Cooke L, Hill C et al. (2010) Associations between children's appetite traits and maternal feeding practices. J Am Diet Assoc 110, 1718-1722.

20. Webber L, Cooke L \& Wardle J (2010) Maternal perceptions of causes and consequences of sibling differences in eating behaviour. Eur J Clin Nutr 64, 1316-1322.

21. Pheasant H (2008) Social, behavioural and other determinants of choice of diet. http://www.healthknowledge.org. $\mathrm{uk} /$ public-health-textbook/disease-causation-diagnostic/2ehealth-social-behaviour/social-behavioural-determinants\#1 (accessed January 2015).
22. Shepherd R (1999) Social determinants of food choice. Proc Nutr Soc 58, 807-812.

23. Gibney M, Margetts B, Kearney J et al. (Editors) (2004) Public Health Nutrition, pp. 147-152. Oxford: WileyBlackwell.

24. European Food Information Council (2005) The determinants of food choice. EUFIC Review 04/2005. http://www. eufic.org/article/en/expid/review-food-choice/ (accessed January 2015).

25. Trichopoulou A, Naska A \& Costacou T; DAFNE III Group (2002) Disparities in food habits across Europe. Proc Nutr Soc 61, 553-558.

26. Musher-Eizenman D, de Lauzon-Guillain B, Holub S et al. (2009) Child and parent characteristics related to parental feeding practices. A cross-cultural examination in the US and France. Appetite 52, 89-95.

27. Capacci S, Mazzocchi M, Shankar B et al. (2002) Policies to promote healthy eating in Europe: a structured review of policies and their effectiveness. Nutr Rev 70, 188-200.

28. Florence MD, Asbridge M \& Veugelers PJ (2008) Diet quality and academic performance. $J$ Sch Health $\mathbf{7 8}$, 209-215.

29. Gorbey HE, Brownawell AM \& Falk MC (2010) Do scientific dietary constituents and supplements affect mental energy? Review of the evidence. Nutr Rev 68, 697-718.

30. Weichselbaum E \& Buttriss J (2011) Nutrition, health and school children. Nutr Bull 36, 295-355.

31. Attuquayefio T \& Stevenson RJ (2015) A systematic review of longer-term dietary interventions on human cognitive function: emerging patterns and future directions. Appetite 95, 554-570.

32. Haapala EA, Eloranta A-M, Venalainen $\mathrm{T}$ et al. (2015) Associations of diet quality with cognition in children - the Physical Activity and Nutrition in Children Study. Br J Nutr 114, 1080-1087.

33. Benton D (2010) The influence of dietary status on the cognitive performance of children. Mol Nutr Food Res 54, 457-470.

34. Hoyland A, Dye L \& Lawton CL (2009) A systematic review of the effect of breakfast on the cognitive performance of children and adolescents. Nutr Res Rev 22, 220-243.

35. Levy L (2013) Breakfast and cognition, review of the literature. https://www.gov.uk/government/uploads/system/ uploads/attachment_data/file/256398/Breakfast_and_cognition _review_FINAL_publication_formatted.pdf (accessed May 2014).

36. Craig B, Hays R, Pickard S et al. (2013) Comparison of US panel vendors for online surveys. J Med Internet Res 15, e260.

37. Khazaal Y, van Singer M, Chatton A et al. (2014) Does selfselection affect samples' representativeness in online surveys? An investigation in online video game research. $J$ Med Internet Res 16, e164.

38. Evans JR \& Mathur A (2005) The value of online surveys. Internet Res 15, 195-219.

39. Blissett J, Meyer C \& Haycraft E (2006) Maternal and paternal controlling feeding practices with male and female children. Appetite 47, 2112-2219.

40. Gage H, von Rosen-von Hoewel J, Laiteinen K et al. (2012) Health effects of infant feeding for parents in leaflets and magazines in five European countries. Public Underst Sci 22, 365-379.

41. Birch LL \& Davison KK (2001) Family environmental factors influencing the developing behavioral controls of food intake and childhood overweight. Pediatr Clin North Am 48, 893-907.

42. Jackson C, Cheater F \& Reid L (2008) A systematic review of decision support needs of parents making child health decisions. Health Expect 11, 232-251. 